J. RADIAT. RES., SUPPLEMEN'T, 103-107 (1991)

A Review of Forty-Five Years Study of Hiroshima and Nagasaki Atomic Bomb Survivors

\title{
I. DOSIMETRY
}

\section{Recalculation of Data on ${ }^{32} \mathbf{P}$ Activity Induced in Sulfur in Hiroshima}

\author{
TATSUJI HAMADA \\ Japan Radioisotope Association, \\ 2-28-45 Honkomagome, Bunkyo-ku, Tokyo 113, Japan
}

\section{Atomic bomb/Neutron induced activity/ ${ }^{32} \mathbf{P} /$ Sulfur}

Historical data for ${ }^{32} \mathrm{P}$ activity induced in sulfur by fast neutrons have been corrected for decay with a recent half-life value of ${ }^{32} \mathrm{P}$ and recalculated with an experimentally determined efficiency ratio of the electroscope for beta rays from ${ }^{32} \mathrm{P}$ and natural uranium used as a standard.

Most samples would have been pure enough so that no correction for the weight of sulfur has been made. The possibility of interference with ${ }^{32} \mathrm{P}$ activity measurements due to induced activity of other elements in the samples could also be excluded.

The revised data show little difference from the original ones except for one sample which contained much impurity. Uncertainty of the data was also discussed.

\section{INTRODUCTION}

F. Yamasaki and A. Sugimoto of the Institute of Physical and Chemical Research were in Hiroshima from 30 Aug. to 6 Sept. 1945 and took several sulfur samples from pole insulators. The samples were sent back to Tokyo and measured for ${ }^{32} \mathrm{P}$ with a Lauritsen electroscope calibrated with $1 \mathrm{~g}$ of oxide of natural uranium $\left(\mathrm{U}_{3} \mathrm{O}_{8}\right)$ prepared to have the same geometry as for sulfur measurement, i.e. spread uniformly over an area of $35 \times 35 \mathrm{~mm}$ on an aluminum plate.

The data, first published in $1953^{1)}$, were then recalculated by Yamasaki using current values of ${ }^{238} \mathrm{U}$ and ${ }^{32} \mathrm{P}$ half-life and taking into consideration and difference of self-absorption of beta rays from ${ }^{32} \mathrm{P}$ and ${ }^{234 m} \mathrm{~Pa}^{2,3)}$.

In the 1983 discussion, the following points were made:

1) Additional contribution, if any, of ${ }^{234} \mathrm{Th}$ soft beta rays emitted from the uranium oxide standard to the calibration of the Lauritsen electroscope should be considered;

2) Effect of impurities in the sulfur samples to the measurements should be examined;

3) Uncertainty of the data should be quoted.

Given below are studies directed to solve the above-mentioned problems ${ }^{4,5}$. 


\section{METHODS}

The efficiency ratio of the electroscope for beta rays from ${ }^{32} \mathrm{P}$ and natural uranium was determined experimentally simulating the work by Yamasaki and Sugimoto with an electroscope of a similar type and a radioactive standard of ${ }^{32} \mathrm{P}$, and in this way the problem of energy difference of beta rays as well as the contribution of ${ }^{234} \mathrm{Th}$ was eliminated.

Impurities in some of the sulfur samples collected by Yamasaki and Sugimoto, some of which still remain intact probably because their activity had been too low, were determined in several ways.

Each sample was dissolved in carbon disulfide and the residue was weighed. The insoluble fraction ranged $0-2.7 \%$ (average $1.18 \%$ ), except for sample $\mathrm{K}-29$. The $\mathrm{CS}_{2}$ insoluble fraction was subjected to neutron activation analysis with a thermal neutron fluence of $6 \times 10^{16} \mathrm{~cm}^{-2}$ and the activated product was measured by gamma-ray spectrometry. Contents of sulfur and other elements in the samples were also determined by $\mathbf{H}$. Takeshita et al. of the National Institute of Radiological Sciences. Content of sulfur was determined by volumetric analysis; while other elements were identified and determined by means of proton-induced X-ray emission method (PIXE).

\section{RESULTS}

The efficiency ratio of the electroscope was found to be 1.09 at the shortest source-window distance, the condition probably adopted by Yamasaki and Sugimoto.

The results of neutron activation analysis of the combined $\mathrm{CS}_{2}$-insoluble fraction of the samples are shown in Table 1. These are compatible with the data obtained by PIXE shown in Table 2.

Table 1. Results of Neutron Activation Analysis of Sulfur Samples

\begin{tabular}{|c|c|c|c|}
\hline \multirow{2}{*}{ Radionuclide } & \multirow{2}{*}{ Half Life } & \multicolumn{2}{|c|}{ Activity $(\mathrm{Bq} / 50 \mathrm{mg})$ after } \\
\hline & & 10 days & 35 days \\
\hline${ }^{46} \mathrm{Sc}$ & $83.8 \mathrm{~d}$ & 73 & 60 \\
\hline${ }^{47} \mathrm{Ca}+{ }^{47} \mathrm{Sc}$ & $4.54 \mathrm{~d}$ & 83 & 1.8 \\
\hline${ }^{59} \mathrm{Fc}$ & $44.6 \mathrm{~d}$ & 36 & 24 \\
\hline${ }^{65} \mathrm{Zn}$ & $244.1 \mathrm{~d}$ & 1640 & 1530 \\
\hline${ }^{76} \mathrm{As}$ & $26.3 \mathrm{~h}$ & 2560 & $3.5 \times 10^{-4}$ \\
\hline${ }^{75} \mathrm{Se}$ & $118.5 \mathrm{~d}$ & 6.7 & 5.8 \\
\hline${ }^{82} \mathrm{Br}$ & $35.4 \mathrm{~d}$ & 10 & $8 \times 10^{-5}$ \\
\hline${ }^{124} \mathrm{Sb}$ & $60.2 \mathrm{~d}$ & 27 & 20 \\
\hline
\end{tabular}


Table 2. Results of Proton-induced X-ray Emission Analysis of Sulfur Samples

\begin{tabular}{|c|c|c|c|c|c|c|c|}
\hline \multirow{2}{*}{ Element } & \multicolumn{6}{|c|}{ Sample No. } & \multirow[b]{2}{*}{$\mathrm{K}-29$} \\
\hline & 1 & 2 & 3 & 11 & 15 & 26 & \\
\hline$S^{a}$ & $100 \%$ & $98.9^{0} \%$ & $98.6 \%$ & $80.7 \%$ & $99.3 \%$ & $100 \%$ & $55.0 \%$ \\
\hline $\mathrm{K}$ & $+t+t$ & ++++ & ++++ & $\mathrm{D}$ & $+++t$ & ++++ & $0.5 \%$ \\
\hline $\mathrm{Ca}$ & ++++ & ++++ & ++++ & $7 \%$ & ++++ & ++++ & $10.0 \%$ \\
\hline $\mathrm{Ti}$ & +++ & $?$ & D & - & ++++ & D & +++ \\
\hline $\mathrm{Cr}$ & ++ & D & - & - & - & ++ & $\mathrm{D}$ \\
\hline $\mathrm{Mn}$ & $?$ & $\mathrm{D}$ & - & $\mathrm{D}$ & ++ & ++ & +++ \\
\hline $\mathrm{Fe}$ & ++ & +++ & $+t+$ & $+t+t$ & ++++ & $++t+$ & $0.2 \%$ \\
\hline $\mathrm{Ni}$ & ++ & - & - & - & - & - & - \\
\hline $\mathrm{Cu}$ & ++ & $\mathrm{D}$ & - & - & + & $+t$ & + \\
\hline $\mathrm{Zn}$ & $++t+$ & ++++ & ++++ & ++ & ++++ & +++ & ++++ \\
\hline As & + & ++ & ++ & $\mathrm{D}$ & D & + & + \\
\hline $\mathrm{Se}$ & ++ & +++ & ++ & ++ & ++ & ++ & ++ \\
\hline $\mathrm{Rb}$ & $\mathrm{D}$ & - & - & - & - & & - \\
\hline $\mathrm{Sr}$ & $\mathrm{D}$ & - & - & ++ & - & - & ++ \\
\hline $\mathrm{La}$ & $?$ & $\mathrm{D}$ & $\mathrm{D}$ & - & - & $\mathrm{D}$ & - \\
\hline $\mathrm{Pb}$ & $\mathrm{D}$ & D & - & - & - & $\mathrm{D}$ & - \\
\hline
\end{tabular}

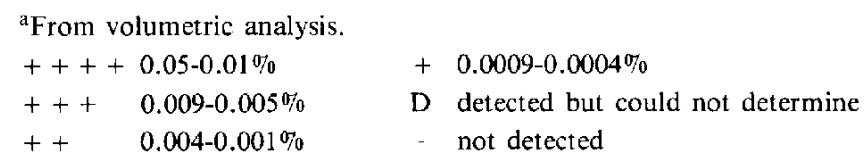

\section{UNCERTAINTY}

Since the fluctuation of electroscope readings cannot easily be estimated from the counting statistics, the standard deviation was determined by repeated reading under the actual measurement conditions. It was found to be about $0.8 \times 10^{-4}$ division per second being almost independent of the activity level. This corresponds to about $0.8 \mathrm{~Bq}$ of ${ }^{32} \mathrm{P}$. The error due to the reproducibility of sample preparation would have been less than $2 \%$. The uncertainty in activity of the ${ }^{32} \mathrm{P}$ standard solution used in the calibration in this work was quoted by the manufacturer to be $+\mathbf{1 . 8}$, $-2.6 \%$. The overall uncertainty of the ${ }^{32} \mathrm{p}$ activity in the samples was thus estimated to be within $1 \mathrm{~Bq}$ at the time of measurement on 1 sigma basis ${ }^{4)}$.

Later, W.C. Roesch of Pacific Northwest Laboratories ${ }^{6}$ noticed that the random fluctuation of electroscope readings should be smaller according to his theoretical study based on the singleevent charge distribution for beta particles.

An appreciable fraction of the actual ionization in the electroscope chamber is, however, due to alpha particles emitted from natural alpha emitters in the atmosphere as well as on the inner surface of the chamber. Assuming that the contribution of the alpha particles in the 
Table 3. Standard Deviations of Electroscope Readings

\begin{tabular}{cccc}
\hline Sample & $\begin{array}{l}\text { Time for } \\
\text { Measurement } \\
(\mathrm{min})\end{array}$ & $\begin{array}{l}\text { Electrometer } \\
\text { Reading } \\
\text { (div/s) }\end{array}$ & $\begin{array}{l}\text { Relative } \\
\text { Standard } \\
\text { Deviation }\end{array}$ \\
\hline Background & 200 & 0.00124 & 0.06 \\
A-4 & 40 & 0.00200 & 0.19 \\
B-5 & 38 & 0.00224 & 0.14 \\
C-6 & 45 & 0.00154 & 0.45 \\
D-12 & 70 & 0.00162 & 0.29 \\
D-12 & 70 & 0.00178 & 0.21 \\
E-13 & 95 & 0.00205 & 0.13 \\
F-14 & 74 & 0.00166 & 0.26 \\
G-15 & 90 & 0.00167 & 0.24 \\
G-15 & 90 & 0.00175 & 0.20 \\
H-7 & 85 & 0.00144 & 0.53 \\
J-8 & 103 & 0.00130 & 1.58 \\
K-29 & b & & \\
\hline
\end{tabular}

${ }^{\text {a}}$ From Yamasaki's record.

${ }^{b}$ No data given.

Table 4. Original and revised data for ${ }^{32} \mathrm{P}$ Activity

\begin{tabular}{lcccc}
\hline Sample & $\begin{array}{c}\text { Ground Distance } \\
(\mathrm{m})\end{array}$ & Original & $\begin{array}{c}32 \mathrm{P} \text { Activity (dpm/gS at ATB) } \\
\text { Revised (1958) }\end{array}$ & Revised (1983) \\
\hline A-4 & 305 & 2200 & 2580 & 2200 \\
B-5 & 178 & 2900 & 3480 & 2940 \\
C-6 & 358 & 900 & 1080 & 880 \\
D-12* & 433 & 1100 & 1380 & 1140 \\
& & & 1920 & 1500 \\
E-13 & 76 & 2000 & 2820 & 2430 \\
F-14 & 417 & 1100 & 1500 & 1260 \\
G-15* & $(440)$ & 1300 & 1620 & 1370 \\
& & & 1920 & 1620 \\
H-7 & 721 & 660 & 720 & 630 \\
J-8 & 1025 & 210 & 240 & 190 \\
K-29 & 682 & 340 & - & 560 \\
& & & & \\
\hline
\end{tabular}

*Yamasaki gave two values for each of these samples in his record. 
measurements by Yamasaki and Sugimoto had been the same as that in the present study, the standard deviation of electroscope readings was calculated as indicated in Table $3^{5 \text { ). }}$.

\section{DISCUSSION}

From the results shown in Tables 1 and 2, it may well be concluded that the interference of impurities with the ${ }^{32} \mathrm{P}$ activity measurements would be negligible even if the samples had contained impurities as much as $5 \%$ by weight. Using a recent value of half-life of ${ }^{32} \mathrm{P}$ and the efficiency ratio of 1.09 , revised data were obtained as shown in Table 4 , where only the data for K-29 was corrected for its higher content of impurity.

\section{REFERENCES}

1. Yamasaki, F, and Sugimoto, A. (1987) Radioactive ${ }^{32} \mathrm{P}$ Produced in Sulfur in Hiroshima. US-Japan Joint Reassessment of Atomic Bomb Radiation Dosimetry in Hiroshima and Nagasaki, Final Report. Volume 2, p.246. Radiation Effects Research Foundation, Hiroshima.

2. Yamasaki, F. (1958) Estimation of Radiation Dose due to the Bombing Attack, Annual Report of Cooperative Research, Japanese Ministry of Education, Radiation Section 33, p.121 (in Japanese).

3. Hamada, T. (1983) Measurement of ${ }^{32} \mathbf{P}$ Activity Induced in Sulfur in Hiroshima. US-Japan Joint Reassessment of Atomic Bomb Radiation Dosimetry in Hiroshima and Nagasaki, p.45. Radiation Effects Research Foundation, Hiroshima.

4. Hamada, T. (1983) ${ }^{32} \mathrm{P}$ Activity Induced in Sulfur in Hiroshima: Reevaluation of Data by Yamasaki and Sugimoto. Second US-Japan Joint Reassessment of Atomic Bomb Radiation Dosimetry in Hiroshima and Nagasaki, p.52. Radiation Effects Research Foundation, Hiroshima.

5. Hamada, T. (1987) Measurements of ${ }^{32} \mathrm{P}$ in Sulfur. US-Japan Joint Reassessment of Atomic Bomb Radiation Dosimetry in Hiroshima and Nagasaki, Final Report. Volume 2, p.272, Radiation Effects Research Foundation, Hiroshima.

6. Roesch, W.C. Private communication. 